\title{
Chronic obstructive pulmonary disease is underdiagnosed and undertreated in São Paulo (Brazil). Results of the PLATINO Study
}

O.A. Nascimento ${ }^{1}$ A. Camelier ${ }^{2}$, F.W. Rosa ${ }^{3}$, A.M.B. Menezes ${ }^{4}$, R. Pérez-Padilla ${ }^{5}$, J.R. Jardim ${ }^{1}$ and Latin American Project for the Investigation of Obstructive Lung Disease (PLATINO) Group 6

\section{Correspondence \\ J.R. Jardim \\ Disciplina de Pneumologia \\ EPM, Unifesp \\ Rua Botucatu, 740, 3ํㅡㄹ Andar \\ 04023-062 São Paulo, SP \\ Brasil \\ Fax: +55-11-5573-5035 \\ E-mail: joserjardim@yahoo.com.br \\ O.A. Nascimento and F.W. Rosa were the recipients of fellowships from CAPES. The PLATINO Study was funded by Boehringer Ingelheim $\mathrm{GmbH}$. The authors declare that they did not receive any advantage from Boehringer Ingelheim $\mathrm{GmbH}$ for the conduction of the study.}

Publication supported by FAPESP.

Received October 29, 2006 Accepted March 28, 2007

\author{
'Disciplina de Pneumologia e Centro de Reabilitação Pulmonar, \\ Escola Paulista de Medicina, Universidade Federal de São Paulo, São Paulo, SP, Brasil \\ 2Disciplina de Pneumologia, Universidade Federal da Bahia, Salvador, BA, Brasil \\ ${ }^{3}$ Curso de Fisioterapia, Universidade Católica de Salvador e da Faculdade de Tecnolo- \\ gia e Ciências, Salvador, BA, Brasil \\ ${ }^{4}$ Programa de Pós-graduação em Epidemiologia, Universidade Federal de Pelotas, \\ Pelotas, RS, Brasil \\ ${ }^{5}$ National Institute of Respiratory Diseases, México, DF, México \\ ${ }^{6}$ PLATINO Group: A.M.B. Menezes (Brazil), J.R. Jardim (Brazil), R. Pérez-Padilla \\ (Mexico), A. Muino (Uruguay), M.V. López (Uruguay), G. Valdivia (Chile), M.M. de Oca \\ (Venezuela), C. Tálamo (Venezuela)
}

\section{Abstract}

Chronic obstructive pulmonary disease (COPD) is a common disease in adults over 40 years of age and has a great social and economic impact. It remains little recognized and undertreated even in developed countries. However, there are no data about its diagnosis and treatment in Brazil. The objectives of the present study were to evaluate the proportion of COPD patients who had never been diagnosed and to determine if the COPD patients who had been identified were receiving appropriate treatment. The Latin American Project for the Investigation of Obstructive Lung Disease (PLATINO) was a randomized epidemiological study of adults over 40 years living in five metropolitan areas, including São Paulo. The studied sample was randomly selected from the population after a division of the metropolitan area of São Paulo in clusters according to social characteristics. All subjects answered a standardized questionnaire on respiratory symptoms, history of smoking, previous diagnosis of lung disease, and treatments. All subjects performed spirometry. The criterion for the diagnosis of COPD was defined by a post-bronchodilator $\mathrm{FEV}_{1} /$ FVC ratio lower than 0.7. A total of 918 subjects were evaluated and 144 (15.8\%) met the diagnostic criterion for COPD. However, 126 individuals $(87.5 \%)$ had never been diagnosed. This undiagnosed group of COPD patients had a lower proportion of subjects with respiratory symptoms than the previously diagnosed patients $(88.9 \mathrm{vs}$ $54.8 \%)$ and showed better lung function with greater $\mathrm{FEV}_{1}(86.8 \pm$ 20.8 vs $68.5 \pm 23.6 \%$ predicted $)$ and FVC $(106.6 \pm 22.4$ vs $92.0 \pm$ $24.1 \%$ predicted). Among the COPD patients, only $57.3 \%$ were advised to stop smoking and $30.6 \%$ received the influenza vaccine. In addition, $82.3 \%$ did not receive any pharmacological treatment. In conclusion, COPD is underdiagnosed and a large number of COPD patients are not treated appropriately.
Key words

- Chronic obstructive

pulmonary disease

- Diagnosis

- Treatment

- Vaccination

- Smoking

- Latin American Project for the Investigation of

Obstructive Lung Disease 


\section{Introduction}

Chronic obstructive pulmonary disease (COPD) is a respiratory disease characterized by chronic airflow obstruction, which is not totally reversible, is generally progressive and is associated with an abnormal inflammatory response of the lungs to the inhalation of particles and toxic gases (1). COPD includes two entities, i.e., chronic bronchitis and emphysema. A diagnosis should be considered in any individual over 40 years old presenting respiratory symptoms and/or a history of exposure to risk factors, particularly smoking. According to the Global Initiative for Chronic Obstructive Lung Disease (GOLD) guidelines, COPD diagnosis is based on a post-bronchodilator forced expiratory volume in $1 \mathrm{~s}\left(\mathrm{FEV}_{1}\right)$ over forced vital capacity $\left(\mathrm{FEV}_{1} / \mathrm{FVC}\right)$ ratio lower than 0.7 (1).

Until the recent publication of data from the PLATINO Study (Latin American Project for the Investigation of Obstructive Lung Disease; 2,3), the only population study on the prevalence of chronic bronchitis in Brazil was performed in Pelotas (RS) and was based only on respiratory symptoms. The prevalence of chronic bronchitis was $12.7 \%$ (4). The PLATINO Study was performed in order to assess COPD prevalence by means of home spirometry in individuals over 40 years of age living in five large metropolitan areas in Latin America (São Paulo, Montevideo, Santiago, Caracas, and Mexico City). In Brazil, COPD prevalence was $15.8 \%$ $(95 \% \mathrm{CI}=13.5-18.1)$, according to a postbronchodilator $\mathrm{FEV}_{1} / \mathrm{FVC}$ ratio lower than 0.7. Apart from its high prevalence, COPD is a disease of great social and economic impact (5). In 2005, more than 174,000 patients were admitted to hospitals covered by the Unified Health System (Sistema Único de Saúde) and diagnosed as having COPD, with the disease resulting in over 30,000 deaths (6).

COPD is underestimated and underdiagnosed globally $(7,8)$, but no statistics about the disease are available for Brazil. Since COPD has a high social and economic impact, the information regarding the undiagnosed proportion of these patients may produce data to be used by health authorities in our country to improve COPD management. COPD therapy has been well-established and is divided into pharmacological and nonpharmacological treatments $(1,9,10)$. Pharmacological treatment includes the use of inhalatory bronchodilators and corticosteroids, stratified according to the stage of the disease, as determined by $\mathrm{FEV}_{1}$. Among non-pharmacological treatments, the two most important measures are smoking cessation and vaccination against influenza. However, it is not known how these guidelines are followed in Brazil. The objectives of the present study were to evaluate the proportion of undiagnosed COPD patients among São Paulo PLATINO Study patients, and to evaluate their pharmacological and non-pharmacological treatment.

\section{Material and Methods}

\section{Study design}

The study was approved by the Ethics and Research Committee of Universidade Federal de São Paulo (Unifesp), São Paulo, SP, Brazil, and was based on data collected by the PLATINO Study. Methods and results on COPD prevalence in Latin America have been previously published $(2,3)$. The PLATINO Study was a transverse study undertaken in order to evaluate COPD prevalence and risk factors in five large metropolitan areas of Latin America, and the São Paulo metropolitan area was chosen in Brazil. The sample studied was selected in several stages. The metropolitan area was first stratified into the main city and surrounding municipalities. These two subsets were further stratified by socioeconomic status. We selected 68 census tracts at each site, taking stratification into account and using a prob- 
ability of selection proportional to the number of households in each tract. Within each tract, we counted the number of people in each household and every count was updated from the most recent census. We chose an average of 15 households using systematic sampling within each tract. All adults aged 40 years or more living in the selected households were invited to participate and were submitted to the evaluations in their own homes after signing an informed consent form to participate in the study. Sample size calculations suggested that 800 people would be needed in each area to estimate a prevalence of up to $30 \%$ with a margin of error of less than 4 percentage points. We aimed to locate about 1020 eligible participants per site, with a predicted $20 \%$ refusal rate.

All interviews and examinations took place at home, and proxy information was not accepted. We obtained data about several factors potentially associated with COPD using a questionnaire that included sections of the American Thoracic Society Division of Lung Diseases (ATS/DLD) (11), European Community Respiratory Health Survey II (12), and Lung Health Study (13) instruments. Questions were related to respiratory symptoms, previous diagnosis of pulmonary diseases, influenza vaccination within the previous year, educational information on smoking cessation, and previous pharmacological treatments. We measured height with a portable stadiometer $\left(\mathrm{Seca}^{\circledR}\right.$, Curitiba, PR, Brazil; precision $0.1 \mathrm{~cm}$ ). Weight was measured with an electronic scale (Tanita ${ }^{\circledR}$, Curitiba, PR, Brazil; precision $200 \mathrm{~g}$ ). Pre- and post-bronchodilator spirometry was performed (Easy-One ${ }^{\circledR}, \mathrm{NDD}$ Medical Technologies, Chelmsford, MA, USA, and Zurich, Switzerland).

\section{Diagnosis of chronic obstructive pulmonary disease}

COPD diagnosis was based on a post- bronchodilator $\mathrm{FEV}_{1} / \mathrm{FVC}$ ratio lower than 0.7 and COPD stage was determined using the most recent version of the GOLD guidelines (14).

\section{Definition of previous diagnosis of pulmonary emphysema, chronic bronchitis and COPD}

The three principal questions that identified a previous diagnosis of pulmonary emphysema, chronic bronchitis and COPD were: 1) "Has your health provider told you that you have lung emphysema?"; 2) "Has your health provider told you that you have chronic bronchitis?", and 3) "Has your health provider told you that you have chronic obstructive pulmonary disease (COPD)?". The absence of a previous diagnosis of emphysema, chronic bronchitis and COPD was considered wherever the subject answered "no" to any of these questions and presented an $\mathrm{FEV}_{1} / \mathrm{FVC}$ ratio lower than 0.7 as assessed by spirometry.

\section{Evaluation of non-pharmacological treatment of COPD}

Smoking cessation and influenza vaccination were determined by means of the following questions: 1) "Has your health provider at any time advised you to stop smoking?", and 2) "Have you taken the influenza vaccination within the last 12 months?".

\section{Evaluation of pharmacological treatment of COPD}

Pharmacological treatment was defined as active when the answer to the question "Have you taken any lung or breathing medication within the last 12 months?" was "yes".

\section{Statistical analysis}

The group of COPD patients was divided into two subgroups: those previously diag- 
nosed as having COPD and those undiagnosed. The two groups were comparable in terms of demographic data and use of pharmacological and non-pharmacological treatment. The numerical data in the descriptive analysis are reported as means $\pm \mathrm{SD}$. Categorical variables are presented as absolute numbers and as a percentage of the total. $\mathrm{FEV}_{1}$ and $\mathrm{FVC}$ are reported as percentages of predicted values for age and height. COPD patients were stratified into stages I, II, III, and IV according to disease severity based on GOLD guidelines. For statistical analysis, stages III and IV were grouped together. The mean values of the numerical variables were compared between groups by the Student $t$-test. Comparison of the proportion of the categorical variables between independ-

Table 1. Demographic characteristics of 144 subjects included in the PLATINO Study of São Paulo.

\begin{tabular}{lc}
\hline Variables & \\
\hline Gender & \\
$\quad$ Male & $73(50.7 \%)$ \\
Female & $71(49.3 \%)$ \\
Age (years) & $59.7 \pm 11.6$ \\
Schooling (years) & $5.0 \pm 4.7$ \\
Skin color & \\
Caucasian & \\
Non-Caucasian & $85(59.0 \%)$ \\
Smoking status & $59(41.0 \%)$ \\
Current smoker & \\
Former smoker & $51(35.4 \%)$ \\
Non-smoker & $45(31.3 \%)$ \\
Smoking consumption & $48(33.3 \%)$ \\
$\quad$ (packs/year) & $18.9 \pm 23.5$ \\
Spirometry & \\
FEV 1 /FVC & \\
FVC (\% predicted) & \\
FEV 1 (\% predicted) & \\
COPD stage & $104.7 \pm 23.1$ \\
Stage I & $84.5 \pm 21.9$ \\
Stage II & \\
Stages III and IV & $90(62.5 \%)$ \\
\hline
\end{tabular}

Data are reported as means \pm SD or number of subjects with percent in parentheses. COPD = chronic obstructive pulmonary disease; $\mathrm{FEV}_{1}=$ forced expiratory volume in $1 \mathrm{~s} ; \mathrm{FVC}=$ forced vital capacity. ent groups was performed by the chi-square test. The level of significance was set at $\mathrm{P}<$ 0.05 in all analyses.

\section{Results}

A total of 984 individuals were interviewed. However, 21 refused to perform the spirometry test, and 45 individuals did not perform the post-bronchodilator spirometry. Thus, a total sample of 918 individuals was submitted to pre- and post-bronchodilator spirometry. Of these 918 individuals, 144 (15.8\%) presented an $\mathrm{FEV}_{1} / \mathrm{FVC}$ ratio lower than 0.7 and were characterized as COPD patients. The demographic data of these COPD patients are presented in Table 1. This sample of COPD patients consisted of $50.7 \%$ males, $59 \%$ Caucasians, with a mean age of 59.7 years and a mean schooling of 5 years. The total group of COPD patients included 51 individuals who were current smokers (35.4\%), 45 former smokers (31.3\%) and 48 non-smokers (33.3\%), with a mean cigarette consumption equal to 18.9 packs/ year. Concerning the pulmonary function values, the mean $\mathrm{FEV}_{1} / \mathrm{FVC}$ ratio for the total sample of COPD patients was 0.62; mean $\mathrm{FEV}_{1}$ was $84.5 \%$ of predicted and mean FVC was $104.7 \%$ of predicted. The stratification of COPD patients into stages according to the GOLD guidelines was as follows: $62.5 \%$ in stage I, $29.9 \%$ in stage II, and $7.6 \%$ in stages III and IV.

\section{Evaluation of a previous diagnosis of lung emphysema, chronic bronchitis and COPD}

Only 3 of the COPD patients studied (2.1\%) had received a previous diagnosis of lung emphysema, 15 (10.4\%) had received a diagnosis of chronic bronchitis and $3(2.1 \%)$ a diagnosis of COPD. When the three diagnoses were grouped, only 18 individuals (12.5\%) had been previously diagnosed as COPD patients (Table 2). When lung function was compared between the previously 
diagnosed COPD and undiagnosed COPD groups, the latter was found to present a higher $\mathrm{FEV}_{1} / \mathrm{FVC}$ ratio $(0.62 \pm 0.08$ vs 0.57 $\pm 0.12)$, higher $\mathrm{FEV}_{1}(86.8 \pm 20.8$ vs $68.5 \pm$ $23.6 \%$ predicted $)$ and FVC $(106.6 \pm 22.4 v s$ $92.0 \pm 24.1 \%$ predicted), which indicate better lung function. Individuals in stages I and II comprised the largest percentage of undiagnosed individuals, 92.2 and $86.0 \%$, respectively, while individuals in stages III and IV presented a smaller proportion of undiagnosed individuals (54.5\%), with a statistically significant difference between them (Table 2). Variables such as gender, age, schooling, race, marital status, and smoking consumption were not statistically different between the two groups. However, when respiratory symptoms were evaluated, it was observed that the previously diagnosed COPD group presented a greater proportion of patients with respiratory symptoms in comparison with the undiagnosed group: chronic cough (44.4 vs 9.5\%), dyspnea (72.2 vs $34.9 \%$ ), wheezing (77.8 vs $34.9 \%$ ), and a combination of any symptoms (88.9 vs $54.8 \%$ ), all of them with statistically significant differences (Figure 1). There was no statistically significant difference in expectoration between the two groups. Other characteristics such as gender, age, schooling, skin color, smoking status, and smoking consumption did not differ between groups (Table 2).

\section{Evaluation of non-pharmacological treatment}

Of the 96 smokers or former smokers in the group of COPD patients, only $55(57.3 \%)$ had been advised to stop smoking. When the groups of previously diagnosed and undiagnosed individuals were compared, no statistical difference was observed (Table 3). When COPD patients were asked about influenza vaccination during the previous year, only 44 individuals $(30.6 \%)$ reported that they had been immunized. No significant difference was observed between previously
Table 2. Comparison of the demographic data between subjects with and without a diagnosis of chronic obstructive pulmonary disease (COPD).

\begin{tabular}{lcc}
\hline Variables & $\begin{array}{c}\text { Previously diagnosed } \\
\text { COPD group }\end{array}$ & $\begin{array}{c}\text { Undiagnosed } \\
\text { COPD group }\end{array}$ \\
\hline $\mathrm{N}$ & $18(12.5 \%)$ & $126(87.5 \%)$ \\
Gender & & \\
$\quad$ Male & $7(38.9)$ & $66(52.4)$ \\
Female & $11(61.1)$ & $60(47.6)$ \\
Age (years) & $60.5 \pm 14.0$ & $59.6 \pm 11.3$ \\
Schooling (years) & $3.7 \pm 3.4$ & $5.2 \pm 5.2$ \\
Skin color & & \\
Caucasian & $9(50.0 \%)$ & $76(60.3 \%)$ \\
Non-Caucasian & $9(50.0 \%)$ & $50(39.7 \%)$ \\
Smoking status & & \\
Current smoker & $4(22.2 \%)$ & $47(37.3 \%)$ \\
Former smoker & $6(33.3 \%)$ & $39(31.0 \%)$ \\
Non-smoker & $8(44.5 \%)$ & $40(31.7 \%)$ \\
Smoking consumption (packs/year) & $14.3 \pm 21.3$ & $19.6 \pm 23.8$ \\
Spirometry & & \\
FEV 1 /FVC & $0.57 \pm 0.12$ & $0.62 \pm 0.08^{*}$ \\
FVC (\% predicted) & $92.0 \pm 24.1$ & $106.6 \pm 22.4^{*}$ \\
FEV $1 \%$ predicted) & $68.5 \pm 23.6$ & $86.8 \pm 20.8^{*}$ \\
COPD stage & & $83(92.2 \%)^{*}$ \\
Stage I & $7(7.8 \%)$ & $67(86.1 \%)$ \\
Stage II & $6(13.9 \%)$ & \\
Stages III and IV & $5(45.5 \%)$ & \\
\hline
\end{tabular}

Data are reported as means \pm SD or number of subjects with percent in parentheses. For abbreviations, see legend to Table 1.

${ }^{*} \mathrm{P}<0.05$ compared to previously diagnosed COPD group (Student $t$-test or chisquare test).

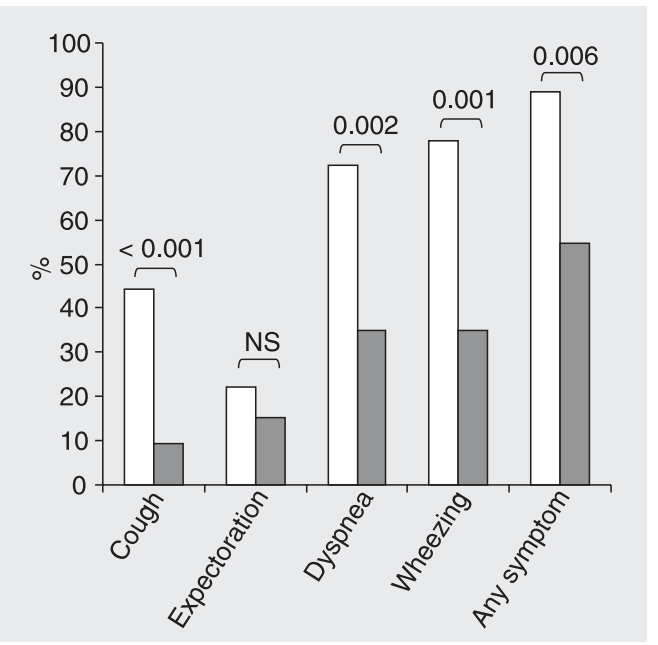

Figure 1. Comparison of the occurrence of symptoms between the group with a previous diagnosis of chronic obstructive pulmonary disease (COPD; open columns) and undiagnosed COPD subjects (filled columns). NS = non-significant (chi-square test). 
diagnosed and undiagnosed individuals (Table 3).

\section{Evaluation of pharmacological treatment}

When individuals were questioned about the use of lung medication within the previous 12 months, only 24 in the group of COPD patients $(16.7 \%)$ reported that they had received medication (Table 3 ). Concerning the whole group of COPD patients, 82 individuals in stage I (91.2\%), 32 in stage II (74.4\%) and 6 in stages III and IV (54.5\%) had not received any medication within the previous year. Among the previously diagnosed COPD group, only nine had used medication within the previous year $(50 \%)$. On the other hand, in the undiagnosed COPD groups only 15 individuals (11.9\%) had received treatment, with a statistically significant difference $(\mathrm{P}=0.001)$.

\section{Discussion}

As far as we know, this is the first study performed in Brazil in order to assess previous diagnosis and therapeutic approach to COPD patients. These results came from the PLATINO Study, which was the first population-based study on the prevalence and impact of COPD in large metropolitan regions of five countries of Latin America (2,3).

Due to the high mortality and the high cost of COPD management and treatment in its most advanced stages, early identifica-

Table 3. Proportion of subjects with and without a previous diagnosis of chronic obstructive pulmonary disease (COPD) who received non-pharmacological or pharmacological treatment.

\begin{tabular}{lccc}
\hline Treatment & $\begin{array}{c}\text { All COPD } \\
\text { subjects }\end{array}$ & $\begin{array}{c}\text { Previously diagnosed } \\
\text { COPD group }\end{array}$ & $\begin{array}{c}\text { Undiagnosed } \\
\text { COPD group }\end{array}$ \\
\hline Smoking cessation & $55(57.3 \%)$ & $7(70.0 \%)$ & $48(55.8 \%)$ \\
Influenza vaccination & $44(30.6 \%)$ & $6(33.3 \%)$ & $38(30.2 \%)$ \\
Pharmacological treatment & $24(16.7 \%)$ & $9(50.0 \%)$ & $15(11.9 \%)^{*}$ \\
\hline
\end{tabular}

Data are reported as means $\pm S D$ or number of subjects with percent in parentheses. ${ }^{*} \mathrm{P}<0.001$ compared to the previously diagnosed COPD group (chi-square test). tion of COPD and appropriate treatment are of the utmost importance to prevent these stages from being reached. It has been reported that the absence of diagnosis of airflow limitation is very common in the general population (15). In the present study, $87.5 \%$ of the individuals diagnosed with COPD by the PLATINO Study indicated that they had never been diagnosed previously. However, the low proportion of undiagnosed individuals is not exclusive to Brazil, with a $40 \%$ rate in Sweden (16) and a $78.2 \%$ rate in Spain (17). In the present study, we observed that undiagnosed COPD patients presented better lung function and fewer respiratory symptoms (chronic cough, dyspnea and wheezing). These data are in accordance with those of other studies. In a Dutch study, it was reported that the absence of diagnosis was associated with a lower smoking load, absence of dyspnea and expectoration (18). On the other hand, a history of smoking and wheezing may be a good predictor of airflow obstruction (19). However, it is difficult to diagnose COPD in its moderate stage on the grounds of clinical evaluation alone without spirometry (20-22) because COPD symptoms are mostly nonspecific and the diagnosis may be delayed. Respiratory symptoms such as chronic cough and expectoration very often are not considered to be important by the patients and may even be neglected by physicians for years. In addition, COPD patients are only diagnosed when they seek medical care, a fact that normally occurs when they are breathless after their daily efforts (23-26). Thus, because of some factors such as slow progression of the disease, the patients may not consider symptoms to be important and the low sensitivity of a clinical examination for the diagnosis of the disease impairs the diagnosis of COPD. Although the clinical features are very important in cases in which COPD is suspected, spirometry is the gold standard for the diagnosis and should be performed. 
When COPD patients stop smoking there may be a reduction in the decline of lung function (27). The proportion of smoking COPD patients who had received any advice on smoking cessation was low (57.3\%), lower than rates observed in two international studies, where it was approximately $70 \%(28,29)$. However, the design of these two studies differed from that of the PLATINO Study: one of them evaluated patients who were admitted to hospitals due to COPD exacerbation (28) and the other evaluated primary health care services (29). Thus, the PLATINO Study results reflect the actual approach to COPD patients in the community and show that advice on smoking cessation should be more widespread in our country.

Vaccination against influenza may reduce morbidity and mortality in COPD patients (30) and should be administered to everyone with the disease, regardless of age. A Spanish study showed that of the individuals who were admitted to hospitals due to COPD exacerbation, $28 \%$ had not been vaccinated against influenza (31); a similar finding was also reported in the United States (32).

Our results showed that $83.3 \%$ of the COPD patients had not been receiving any pharmacological treatment over the last year. In Spain, it was reported that only $19.3 \%$ of COPD patients were receiving any drug treatment. In addition, less than half of the severe and very severe cases $\left(\mathrm{FEV}_{1}<50 \%\right)$ were receiving any treatment for respiratory disease (17). The recommendations for pharmacological treatment are not dependent on the presence of symptoms. All moderate, severe and very severe patients $\left(\mathrm{FEV}_{1}\right.$ less than $80 \%$ ) according to the Brazilian Consensus in COPD (10), GOLD (14) or ATS/ ERS Guidelines (9) are advised to receive pharmacological treatment continuously. This situation was also common in other studies performed in Europe. In a British study, it was shown that only $36.9 \%$ of the individuals affected by respiratory diseases (asthma or COPD) used bronchodilators or inhalatory corticosteroids (33). These data show that the low rate of COPD patients under treatment is not an exclusive feature of Brazil. Our study has demonstrated that COPD patients do not usually receive the recommended pharmacological and nonpharmacological treatments. The most plausible reason for this may be related to the absence of a COPD diagnosis, as shown in the previously diagnosed COPD group which presented a higher proportion of subjects receiving pharmacological treatment (Table 3). If the patients have not been diagnosed, they will not be treated. In addition, the underdiagnosed group presented a smaller proportion of respiratory symptoms, which may have been responsible for the underdiagnosis of the disease. Consequently, if the patients have fewer symptoms they will be less diagnosed and less treated. On the other hand, the patients were asked if they had used any medication over the previous year and not if these medications had been prescribed by a physician. So, it was impossible to know if medication was prescribed and had not been taken by the patient. Selfmedication is a common practice in Brazil, which makes it impossible to know, with the tools used in this study, at what point there was failure of the pharmacological treatment.

The main limitation of the present study is the spirometry criterion for COPD diagnosis, since severe asthmatic individuals and those over 70 years of age may present an $\mathrm{FEV}_{1} / \mathrm{FVC}$ ratio lower than 0.7. However, it is not possible to differentiate asthma and COPD in an individual over 40 years old by spirometry alone (34-36), although the use of the post-bronchodilator spirometry value is supposed to reduce the false-positive cases. However, the spirometry criterion adopted in our study is the one most commonly described in the COPD documents $(9,10)$ and used in epidemiological studies (37-39) and allows us to compare our results to those of 
other studies. These patients were not excluded from the sample because, for COPD epidemiological studies, the international criterion for a diagnosis of COPD is a postbronchodilator $\mathrm{FEV}_{1} / \mathrm{FVC}$ ratio lower than $0.7(9,10,14)$. The adoption of this criterion definitely involves the risk of including asthmatics or normal aged people. However, we should point out that spirometry was performed after the inhalation of a bronchodilator, which is the routine test used to exclude all mild and moderate asthmatics. Besides, it is a consensus that the final individual diagnosis of asthma should always be made on a clinical basis. This fixed ratio criterion should be seen as a tool for population screening. This diagnostic criterion is recommended by the GOLD guidelines and has become the most widely used one due to its feasibility and better capacity for increasing the diagnosis of COPD.

This study demonstrated that COPD is underdiagnosed and undertreated in Brazil. These facts can generate higher impact to COPD patients such as higher morbidity and mortality and higher lung function rate decline. A better screening program is needed to improve the treatment of these patients and to reduce the impact of the disease in their lives.

\section{References}

1. Pauwels RA, Buist AS, Calverley PM, Jenkins CR, Hurd SS. Global strategy for the diagnosis, management, and prevention of chronic obstructive pulmonary disease. NHLBI/WHO Global Initiative for Chronic Obstructive Lung Disease (GOLD) Workshop summary. Am J Respir Crit Care Med 2001; 163: 1256-1276.

2. Menezes AM, Jardim JR, Perez-Padilla R, Camelier A, Rosa F, Nascimento O, et al. Prevalence of chronic obstructive pulmonary disease and associated factors: the PLATINO Study in São Paulo, Brazil. Cad Saúde Pública 2005; 21: 1565-1573.

3. Menezes AM, Perez-Padilla R, Jardim JR, Muino A, Lopez MV, Valdivia $\mathrm{G}$, et al. Chronic obstructive pulmonary disease in five Latin American cities (the PLATINO study): a prevalence study. Lancet 2005; 366: 1875-1881.

4. Menezes AM, Victora CG, Rigatto M. Prevalence and risk factors for chronic bronchitis in Pelotas, RS, Brazil: a population-based study. Thorax 1994; 49: 1217-1221.

5. Sin DD, Stafinski T, Ng YC, Bell NR, Jacobs P. The impact of chronic obstructive pulmonary disease on work loss in the United States. Am J Respir Crit Care Med 2002; 165: 704-707.

6. Ministério da Saúde. Informações em saúde: Mortalidade. http:// www.datasus.gov.br. Accessed May 25, 2006.

7. Mclvor RA, Tashkin DP. Underdiagnosis of chronic obstructive pulmonary disease: a rationale for spirometry as a screening tool. Can Respir J 2001; 8: 153-158.

8. van Weel C. Underdiagnosis of asthma and COPD: is the general practitioner to blame? Monaldi Arch Chest Dis 2002; 57: 65-68.

9. Celli BR, MacNee W. Standards for the diagnosis and treatment of patients with COPD: a summary of the ATS/ERS position paper. Eur Respir J 2004; 23: 932-946.

10. Jardim JR, Oliveira JC, Nascimento O. II Consenso Brasileiro sobre Doença Pulmonar Obstrutiva Crônica (DPOC). J Bras Pneumol 2004; 30 (Suppl 5): S1-S42.

11. Ferris BG. Epidemiology Standardization Project (American Thoracic Society). Am Rev Respir Dis 1978; 118: 1-120.

12. The European Community Respiratory Health Survey II. Eur Respir
J 2002; 20: 1071-1079

13. BC Cancer Research Centre. Lung Health Study Questionnaire. Vancouver: BC Cancer Research Centre; 2004.

14. Fabbri LM, Hurd SS. Global Strategy for the Diagnosis, Management and Prevention of COPD: 2003 update. Eur Respir J 2003; 22: 1-2.

15. Coultas DB, Mapel D, Gagnon R, Lydick E. The health impact of undiagnosed airflow obstruction in a national sample of United States adults. Am J Respir Crit Care Med 2001; 164: 372-377.

16. Lindstrom $\mathrm{M}$, Jonsson $\mathrm{E}$, Larsson $\mathrm{K}$, Lundback $\mathrm{B}$. Underdiagnosis of chronic obstructive pulmonary disease in Northern Sweden. Int $J$ Tuberc Lung Dis 2002; 6: 76-84.

17. Pena VS, Miravitlles M, Gabriel R, Jimenez-Ruiz CA, Villasante C Masa JF, et al. Geographic variations in prevalence and underdiagnosis of COPD: results of the IBERPOC multicentre epidemiological study. Chest 2000; 118: 981-989.

18. Vrijhoef HJ, Diederiks JP, Wesseling GJ, van Schayck CP, Spreeuwenberg C. Undiagnosed patients and patients at risk for COPD in primary health care: early detection with the support of non-physicians. J Clin Nurs 2003; 12: 366-373.

19. Holleman DR Jr, Simel DL, Goldberg JS. Diagnosis of obstructive airways disease from the clinical examination. J Gen Intern Med 1993; 8: 63-68

20. Badgett RG, Tanaka DJ, Hunt DK, Jelley MJ, Feinberg LE, Steiner $\mathrm{JF}$, et al. Can moderate chronic obstructive pulmonary disease be diagnosed by historical and physical findings alone? Am J Med 1993; 94: 188-196.

21. Badgett RG, Tanaka DJ, Hunt DK, Jelley MJ, Feinberg LE, Steiner JF, et al. The clinical evaluation for diagnosing obstructive airways disease in high-risk patients. Chest 1994; 106: 1427-1431.

22. Holleman DR Jr, Simel DL. Does the clinical examination predic airflow limitation? JAMA 1995; 273: 313-319.

23. Sherrill DL, Lebowitz MD, Knudson RJ, Burrows B. Longitudinal methods for describing the relationship between pulmonary function, respiratory symptoms and smoking in elderly subjects: the 
Tucson Study. Eur Respir J 1993; 6: 342-348.

24. Sherman CB, Xu X, Speizer FE, Ferris BG Jr, Weiss ST, Dockery $D W$. Longitudinal lung function decline in subjects with respiratory symptoms. Am Rev Respir Dis 1992; 146: 855-859.

25. Vestbo J, Prescott E, Lange P. Association of chronic mucus hypersecretion with FEV1 decline and chronic obstructive pulmonary disease morbidity. Copenhagen City Heart Study Group. Am J Respir Crit Care Med 1996; 153: 1530-1535.

26. Lange P, Nyboe J, Appleyard M, Jensen G, Schnohr P. Relation of ventilatory impairment and of chronic mucus hypersecretion to mortality from obstructive lung disease and from all causes. Thorax 1990; 45: 579-585.

27. Fletcher $\mathrm{C}$, Peto R. The natural history of chronic airflow obstruction. Br Med J 1977; 1: 1645-1648.

28. Fritsch K, Jacot ML, Klarer A, Wick F, Bruggmann P, Krause M, et al. Adherence to the Swiss guidelines for management of COPD: experience of a Swiss teaching hospital. Swiss Med Wkly 2005; 135: 116-121.

29. Takahashi T, Ichinose M, Inoue H, Shirato K, Hattori T, Takishima T. Underdiagnosis and undertreatment of COPD in primary care settings. Respirology 2003; 8: 504-508.

30. Nichol KL, Margolis KL, Wuorenma J, von Sternberg T. The efficacy and cost effectiveness of vaccination against influenza among elderly persons living in the community. N Engl J Med 1994; 331: 778784.

31. Garcia-Aymerich J, Barreiro E, Farrero E, Marrades RM, Morera J, Anto JM. Patients hospitalized for COPD have a high prevalence of modifiable risk factors for exacerbation (EFRAM study). Eur Respir J 2000; 16: 1037-1042.
32. Nichol KL, Baken L, Nelson A. Relation between influenza vaccination and outpatient visits, hospitalization, and mortality in elderly persons with chronic lung disease. Ann Intern Med 1999; 130: 397403.

33. Renwick DS, Connolly MJ. Prevalence and treatment of chronic airways obstruction in adults over the age of 45 . Thorax 1996; 51 : 164-168.

34. Bakke PS, Baste V, Hanoa R, Gulsvik A. Prevalence of obstructive lung disease in a general population: relation to occupational title and exposure to some airborne agents. Thorax 1991; 46: 863-870.

35. Brotons B, Perez JA, Sanchez-Toril F, Soriano S, Hernandez J, Belenguer JL. The prevalence of chronic obstructive pulmonary disease and asthma. A cross-sectional study. Arch Bronconeumol 1994; 30: 149-152.

36. Marco JL, Martin Berra JC, Corres IM, Luque DR, Zubillaga GG. Chronic obstructive lung disease in the general population. An epidemiologic study performed in Guipuzcoa. Arch Bronconeumol 1998; 34: 23-27.

37. Celli BR, Halbert RJ, Nordyke RJ, Schau B. Airway obstruction in never smokers: results from the Third National Health and Nutrition Examination Survey. Am J Med 2005; 118: 1364-1372.

38. Kim DS, Kim YS, Jung KS, Chang JH, Lim CM, Lee JH, et al. Prevalence of chronic obstructive pulmonary disease in Korea: a population-based spirometry survey. Am J Respir Crit Care Med 2005; 172: 842-847.

39. Mannino DM, Buist AS, Petty TL, Enright PL, Redd SC. Lung function and mortality in the United States: data from the First National Health and Nutrition Examination Survey follow up study. Thorax 2003; 58: 388-393. 